\title{
Valor nutritivo de plantas forrageiras anuais de inverno em quatro épocas de semeadura
}

\author{
Nutritive value of five cool-season forage species under four sowing dates
}

\author{
André Brugnara Soares ${ }^{\mathrm{I}}$ Edison Antônio Pin ${ }^{\mathrm{II}}$ Jean Carlo Possenti ${ }^{\mathrm{III}}$
}

\section{RESUMO}

O presente trabalho teve por objetivo avaliar o valor nutritivo de aveia branca (IPR 126), aveia preta (IAPAR 61), aveia preta comum, azevém comum e trigo duplo propósito (BRS Tarumã), semeados em épocas distintas (04 e 24 de abril, 14 de maio e 03 de junho de 2008). O delineamento experimental utilizado foi o de blocos ao acaso com quatro repetições. Os cortes foram realizados em função da altura do dossel, variando para cada espécie, assim com a altura do corte. $O$ material colhido foi analisado quanto aos teores de proteína bruta (PB), Fibra em detergente neutro (FDN) e nutrientes digestiveis totais (NDT). Houve interação significativa entre épocas de semeadura e forrageiras sobre todas as variáveis nutricionais avaliadas. $O$ percentual de PB e o NDT das aveias e do azevém foram maiores nas semeaduras precoces enquanto que o percentual de FDN aumentou nas semeaduras tardias. Comportamento contrastante foi verificado no trigo BRS Tarumã o qual apresentou menor valor nutritivo na semeadura precoce.

Palavras-chave: gramíneas anuais de inverno, pastagem de inverno, valor nutritivo.

\section{ABSTRACT}

This trial aimed to evaluate the nutritive value of white oat (IPR 126), black oat (IAPAR 61), common black oat, common annual ryegrass and dual purpose wheat (BRS Tarumã), sowed on different dates $\left(4^{\text {th }}\right.$ and $24^{\text {th }}$ April, May $14^{\text {th }}$, and June $3^{\text {rd }}$ 2008). Randomized completely block design was used with four replicates. Cutting regime was done according to sward surface height target, varying to each forage species, as well as stubble height. Harvested material was analyzed in terms of crude protein content $(C P)$, neutral detergent fiber $(N D F)$ and total digestible nutrients (TDN). There was significant interaction between sowing dates and forage species over all nutritive variables analyzed. CP and TDN of oats and ryegrass were higher in early sowing dates, and NDF content increased in the latest sowing dates. On the contrary, BRS 'Tarumã' had lesser nutritive value in earliest sowing date.

Key words: annual cool-season grasses, winter pasture, nutritive value.

\section{INTRODUÇÃO}

As propriedades rurais vêm buscando opções que intensifiquem o uso da terra e aumentem a sustentabilidade dos sistemas de produção com incremento na renda. Na produção animal a pasto, o desafio é constante, momento em que se busca uma estabilidade de produção mantida com a quantidade $\mathrm{e}$ a qualidade dos volumosos o ano todo. Nos sistemas de integração lavoura-pecuária, podem-se produzir, nas mesmas áreas de terra, fontes de proteína por meio das forrageiras de inverno e de energia com a produção de grãos no verão, milho e soja (NEUMANN \& LUPATINI, 2002), que pode ser destinada à comercialização de grãos ou uso para alimentação dos animais dentro da propriedade. Essa característica vem reforçando o interesse pela utilização de gramíneas mais adaptadas às condições que ocorrem durante a estação fria na região sul do Brasil.

'Universidade Tecnológica Federal do Paraná (UTFPR), Campus Pato Branco, 85503-390, Pato Branco, PR, Brasil. E-mail: soares@utfrp.edu.br. Autor para correspondência.

IIPrograma de Pós-graduação em Agronomia, UTFPR Campus Pato Branco, Pato Branco, PR, Brasil.

IIICurso de Agronomia - Estação Experimental, UTFPR, Campus Dois Vizinhos, Dois Vizinhos, PR, Brasil. 
A aveia forrageira é climaticamente adaptada à região sul do país e sua qualidade irá depender do manejo ao qual foi submetida (ALVIN \& CÓSER, 2000). $\mathrm{O}$ azevém desenvolve-se melhor em temperaturas entre $18 \mathrm{a} 23^{\circ} \mathrm{C}$, registradas entre outono e início da primavera, sendo recomendada semeadura entre março a maio, e sua produção supera $10 \mathrm{t} \mathrm{MS} \mathrm{ha-1} \mathrm{com} \mathrm{12,7 \%} \mathrm{de} \mathrm{PB} \mathrm{e}$ $54,4 \%$ de FDN (ALVES FILHO et al., 2003). O trigo 'BRS Tarumã' é considerado uma variedade semi-tardia, podendo ser semeada na segunda quinzena de abril e início de maio (DEL DUCA et al., 2004). Essa cultivar no Sudoeste do Paraná, entre os meses de julho a outubro, alcançou teores médios de 19,1\% PB, 71,1\% NDT e 51,9\% de FDN em regime de pastejo (PITTA, 2009).

Durante os estádios de crescimento das plantas, ocorrem variações nos níveis nutritivos, diminuindo a quantidade de folhas, teor de $\mathrm{PB}$ e minerais. Ao mesmo tempo, eleva-se o percentual de colmos no dossel e fibra bruta, reduzindo a digestibilidade e o consumo da pastagem (BLASER, 1988).

No entanto, a maioria dos trabalhos científicos não se preocupa em discutir a distribuição qualitativa no tempo que estaria influenciando diretamente no desempenho dos rebanhos. Aliado a isso, destaca-se o considerável número de cultivares de espécies forrageiras de inverno disponíveis e que nem sempre se tem resultados consistentes quanto à dinâmica no valor nutritivo dessas plantas no decorrer dos seus ciclos, especialmente quando influenciados pela época de semeadura. Nesse enfoque, teve-se como objetivo avaliar as espécies de forrageiras de estação fria em quatro épocas de semeadura, fazendo uma análise da dinâmica nutricional das cultivares durante a estação fria do ano.

\section{MATERIAL E MÉTODOS}

O experimento foi conduzido no período de 04 de abril a 18 de setembro de 2008, na Estação Experimental da Universidade Tecnológica Federal do Paraná, Campus Dois Vizinhos (latitude 25 44' 57" S e longitude $53^{\circ} 03^{\prime} 41^{\prime \prime} \mathrm{O}$ ), com altitude de $534 \mathrm{~m}$, na região Sudoeste do Paraná, situado fisiograficamente no Terceiro Planalto Paranaense (MAAK, 1968). O clima da região, segundo a classificação de Koepen, caracteriza-se como subtropical úmido, tipo Cfa. A precipitação média mensal é de $177 \mathrm{~mm}$, a temperatura média do mês mais frioé inferior a $14,7^{\circ} \mathrm{C}$ (mesotérmico) e a temperatura do mês mais quente situa-se acima de $25,2^{\circ} \mathrm{C}$, com verões quentes e geadas frequentes (IAPAR, 2008).

O solo pertence à Unidade de mapeamento nitossolo vermelho distroférrico úmbrico, textura argilosa, fase floresta subtropical perenifólia e relevo ondulado (BHERING et al., 2008), cuja análise química revelou os seguintes valores: $\mathrm{pH}$ em $\mathrm{CaCl}=5,4$; M.O. $=29,48 \mathrm{~g} \mathrm{dm}^{-3} ; \mathrm{P}=7,08 \mathrm{mg} \mathrm{dm}^{-3} ; \mathrm{K}=0,18 \mathrm{cmol}_{\mathrm{c}} \mathrm{dm}^{-3}$; $\mathrm{Cu}=5,01 \mathrm{mg} \mathrm{dm}^{-3} ; \mathrm{Fe}=86,97 \mathrm{mg} \mathrm{dm}^{-3} ; \mathrm{Zn}=3,61 \mathrm{mg} \mathrm{dm}^{-3}$; $213,50 \mathrm{mg} \mathrm{dm}^{-3} ; \mathrm{Al}^{+3}=0,00 \mathrm{cmol}_{\mathrm{cdm}} \mathrm{dm}^{-3} ; \mathrm{H}+\mathrm{Al}=3,68 \mathrm{cmol}_{\mathrm{c}} \mathrm{dm}^{-3}$; $\mathrm{Ca}=5,87 \mathrm{cmol}_{\mathrm{c}} \mathrm{dm}^{-3} ; \mathrm{Mg}=3,93 \mathrm{cmol}_{\mathrm{c}} \mathrm{dm}^{-3} ; \mathrm{SB}=9,98 \mathrm{cmol}_{\mathrm{c}}$ $\mathrm{dm}^{-3} \mathrm{eV}=73,06 \%$.

A área experimental é utilizada desde 1998 no sistema plantio direto, com rotação de soja e milho no verão e, no inverno, aveia como cobertura ou trigo para produção agrícola. Após a colheita da soja, realizaram-se tratos culturais com o uso da enxada rotativa e adubação, de acordo com as recomendações técnicas da CQFS (2004). Não houve a necessidade de calagem e a fertilização do solo foi feita manualmente a lanço, consistindo da adubação de base com $15 \mathrm{~kg} \mathrm{ha}^{-1}$ de N, $75 \mathrm{~kg} \mathrm{ha}^{-1} \mathrm{de}_{2} \mathrm{O}_{5}$ e $45 \mathrm{~kg} \mathrm{ha}^{-1}$ de $\mathrm{K}_{2} \mathrm{O}$ por ocasião de cada semeadura. A adubação de cobertura constou de $60 \mathrm{~kg} \mathrm{ha}^{-1} \mathrm{de} \mathrm{N}$, na forma de ureia, parcelada em três aplicações, distribuídas a lanço 30, 45 e 60 dias após cada data de semeadura.

Os tratamentos foram arranjados em esquema fatorial $4 \times 5$, quatro épocas de semeadura e cinco cultivares. O delineamento experimental foi o de blocos ao acaso com quatro repetições. Cada unidade experimental teve uma área de $9 \mathrm{~m}^{2}(3 \times 3)$, totalizando $1.200 \mathrm{~m}^{2}$. As épocas de semeaduras foram 04 e 24 de abril, 14 de maio e 03 de junho de 2008. As espécies/ cultivares utilizadas foram Avena sativa cv. 'IPR 126' $\left(60 \mathrm{~kg} \mathrm{ha}^{-1}\right)$, Avena strigosa Schreb cv. 'IAPAR 61 Ibiporã' (60kg ha $\left.{ }^{-1}\right)$; Avena strigosa cv. 'Comum' $(60 \mathrm{~kg}$ ha $\left.^{-1}\right)$; Lolium multiflorum Lam. cv. 'Comum' (35 $\left.\mathrm{kg} \mathrm{ha}^{-1}\right)$ e trigo Triticum aestivum L. cv. 'BRS Tarumã' (140kg $\left.\mathrm{ha}^{-1}\right)$. A semeadura foi realizada a lanço e as sementes incorporadas ao solo com o uso de ancinho a uma profundidade de $2 \mathrm{~cm}$.

A massa de forragem foi obtida por meio de cortes em uma área de $0,25 \mathrm{~m}^{2}$, quando as espécies chegavam à altura pretendida. Os cortes ocorriam quando as plantas atingiram as alturas médias de $30 \mathrm{~cm}$, $25 \mathrm{~cm}$ e $30 \mathrm{~cm}$, respectivamente, para as aveias, azevém e trigo, sendo os cortes efetuados a sete centímetros em relação à superfície do solo. O número de cortes foi variável para cada espécie forrageira e para as distintas épocas de semeadura. Enquanto as aveias proporcionaram, em média, quatro cortes, o trigo e o azevém apresentaram somente dois. Em seguida a cada corte, as parcelas eram uniformizadas quanto a sua altura, por meio de roçadeira costal.

As amostras coletadas foram secas em estufa de ventilação forçada a $65^{\circ} \mathrm{C}$ até peso constante e, posteriormente, trituradas em moinho tipo Willey, com peneira de um milímetro para realização da análise bromatológica. As variáveis avaliadas foram: teor de 
proteína bruta $(\mathrm{PB}, \%)$, teor de fibra em detergente neutro (FDN, \%), teor de nutrientes digestíveis totais (NDT, \%). As análises foram feitas pelo método de reflectância de radiação infravermelha (NIRS), como descrito por MARTEN et al. (1985).

Os resultados obtidos foram submetidos à análise de variância para verificar a possível interação entre épocas de semeadura e cultivares. Fez-se a comparação múltipla de média entre os tratamentos pelo teste de Duncan a $1 \%$ de significância e as modificações no fator tempo pela análise de regressão polinomial. Para proceder às análises estatísticas, utilizou-se o programa SANEST (ZONTA \& MACHADO, 1984).

\section{RESULTADOS E DISCUSSÃO}

Houve interação significativa $(\mathrm{P}<0,05)$ entre material forrageiro e época de semeadura para todas as variáveis, indicando a importância de se avaliar a combinação correta desses fatores. A época de semeadura é um fator que determina as variáveis ambientais que estarão interagindo com a genética da planta, podendo, em termos práticos, interferir nos teores nutricionais dela. Para a variável PB (Tabela 1), observase que, na primeira época de semeadura, as aveias apresentaram teores de proteína bruta elevados com médias de $22,2 \%$, sendo que o trigo 'BRS Tarumã' apresentou o menor teor entre as cultivares $(17,4 \%)$. Os genótipos avaliados apresentaram diferentes respostas fisiológicas em função do ambiente. Para os trigos de inverno, a soma térmica e o fotoperíodo são determinantes na indução à floração, influenciando no seu ciclo. Acultivar 'BRS Tarumã' semi-tardia evidenciou seu comportamento sensível à vernalização. A relação folha/colmo também sofre mudanças nas semeaduras mais tardias, pois, com o adiantamento fisiológico, ocorre o alongamento do colmo e diminuição das folhas, tornando as plantas mais fibrosas. De maneira geral, o valor nutritivo dos genótipos testados apresentou resposta biológica em função dos ciclos dos materiais e das épocas de semeadura.

Na segunda época, observou-se redução dos teores de proteína para a aveia IAPAR 61 e o azevém, quando comparado com a primeira, ao contrário do que foi observado para o trigo BRS Tarumã, em que houve um aumento de $17 \%$ no teor de PB. Comparando as forrageiras, observou-se que a aveia Comum apresentou maior teor de $\mathrm{PB}$, não diferindo significativamente das demais aveias e do trigo BRS Tarumã. PRIMAVESI et al. (2001), trabalhando com a aveia IAPAR 61, encontraram teores médios de 16,9 e $18,1 \%$ de PB, em dois anos de experimento na região de São Carlos - SP, em cortes feitos com 28 e 56 dias e adubações nitrogenadas antes e após os cortes. Valores semelhantes foram encontrados por RODRIGUES et al. (2002) que, em três anos de pesquisa com aveia IAPAR 61 e azevém, obtiveram, em média, respectivamente, 16,0 e $16,5 \%$ de $\mathrm{PB}$, sendo as semeaduras realizadas no início do outono e cortes realizados no período vegetativo e florescimento (RODRIGUES et al., 2002). A média superior de proteína bruta obtida neste trabalho provavelmente ocorreu devido aos cortes terem sido realizados em função da altura de plantas e não em dias pré-estabelecidos, o que promoveu maior número de perfilhos e folhas novas, que apresentam maior teor de nitrogênio, consequentemente maior teor de proteína bruta.

Comparando a terceira época de semeadura com as primeiras, observou-se diminuição do teor de proteína para todas as forrageiras, exceto para o trigo BRS Tarumã. Este material, por sua vez, apresentou aumento de $36 \%$ em relação à primeira época.

$\mathrm{Na}$ quarta época de semeadura, foram observados os menores teores de proteína bruta para todas as forrageiras, sendo que as três aveias apresentaram média de 18,4\%, o azevém comum $15,8 \%$

Tabela 1 - Teor médio de proteína bruta de forrageiras anuais de inverno (PB, \%) em diferentes épocas de semeadura. Dois Vizinhos - PR, 2008.

\begin{tabular}{|c|c|c|c|c|c|}
\hline \multirow{2}{*}{ Forrageira } & \multicolumn{5}{|c|}{--Época de semeadura--- } \\
\hline & 04 abril & 24 abril & 14 maio & 03 junho & Média \\
\hline Av. IPR 126 & $20,2 \mathrm{Aba}$ & $20,6 \mathrm{Aa}$ & $18,9 \mathrm{BCb}$ & $17,6 \mathrm{ABb}$ & 19,3 \\
\hline Av. IAPAR 61 & $22,7 \mathrm{Aa}$ & $21,9 \mathrm{Ab}$ & $21,1 \mathrm{Ab}$ & $18,7 \mathrm{Abc}$ & 21,1 \\
\hline Av. comum & $23,7 \mathrm{Aa}$ & $23,0 \mathrm{Aa}$ & $20,5 \mathrm{ABCb}$ & $18,8 \mathrm{Ac}$ & 21,5 \\
\hline Az. Comum & $19,7 \mathrm{Aa}$ & $17,0 \mathrm{Bb}$ & $16,6 \mathrm{Cbc}$ & $15,8 \mathrm{Bc}$ & 17,3 \\
\hline Trigo Tarumã & $17,4 \mathrm{Bc}$ & $20,3 \mathrm{ABb}$ & $23,6 \mathrm{Aa}$ & $20,9 \mathrm{Ab}$ & 20,5 \\
\hline Média & 20,7 & 20,6 & 20,1 & 18,4 & \\
\hline
\end{tabular}

Valores seguidos de mesma letra maiúscula na coluna e minúscula na linha não diferem significativamente entre si pelo Teste de Duncan a $1 \%$. 
e o trigo BRS Tarumã 20,9\%. FEROLLA et al. (2008), em três épocas de semeadura na região Sudeste do Brasil, com intervalo de avaliação de trinta dias, utilizando a aveia preta, encontrou teores de proteína bruta de $16,12 \%, 22,38 \%$ e $21,94 \%$, respectivamente, para as semeaduras realizadas em abril, maio e junho, valores próximos aos encontrados neste trabalho.

CECATO et al. (1998), cultivando aveia em sistema de irrigação na região norte do estado do Paraná, com aplicação de $45 \mathrm{~kg}_{\text {de }} \mathrm{N} \mathrm{ha}^{-1}$ antes e depois do primeiro corte, encontrou teores de proteína bruta para a aveia preta comum de $17,9 \%$ e, para a IAPAR 61 , de $20,6 \%$. No presente experimento, a aveia preta comum apresentou $20,5 \%$ de PB e a IAPAR $6121,1 \%$ de $\mathrm{PB}$ utilizando $60 \mathrm{~kg}$ de $\mathrm{N} \mathrm{ha}^{-1}$ em cobertura antes do primeiro corte. PIAZETTA (2007), avaliando o valor nutritivo da aveia IAPAR 61 em relação à altura de pastejo, observou que, em maior intensidade $(7 \mathrm{~cm})$, os valores de PB e FDN foram de $23,80 \%$ e $58,51 \%$ e, em menor intensidade de pastejo $(28 \mathrm{~cm})$, os teores médios de PB e FDN foram, respectivamente, 20,92 e 60,48\%, utilizando $150 \mathrm{~kg}$ de $\mathrm{N} \mathrm{ha}^{-1}$ em duas aplicações.

ROCHA et al. (2007), trabalhando com diferentes cultivares de azevém, verificaram diminuição nos teores de proteína bruta à medida que os cortes foram sendo realizados. Os valores finalizaram com médias de 20,1\% de PB, superiores à média obtida nas quatro épocas de semeadura do presente estudo, que foi $17,3 \%$.

Para a variável teor de NDT (Tabela 2), observou-se que, para todas as forrageiras, exceto para o trigo BRS Tarumã, o atraso na época de semeadura proporciona diminuição nos teores de NDT, indicando que semeaduras mais precoces tendem a fornecer forragem de maior valor nutritivo. O NDT possui correlação direta com a PB e ambos correlação inversa com o teor de FDN, pois, quanto mais tardias forem as semeaduras, a PB e NDT diminuem (Tabela 1 e 2) e a fibra em detergente neutro aumenta (Tabela 3 ).

Comparando as forrageiras nas épocas de semeadura, observou-se que, na primeira época, a aveia IAPAR 61 apresentou o maior teor de NDT, não diferindo estatisticamente das demais aveias e do azevém, sendo que trigo BRS Tarumã apresentou o menor teor de NDT. Na segunda semeadura, não houve diferença significativa entre as forrageiras avaliadas, apresentando, em média, teor de 67,5\% de NDT. Já na terceira e quarta época de semeadura, o trigo BRS Tarumã apresentou os maiores teores de NDT, indicando que, para esta espécie, semeaduras mais tardias proporcionam maior valor nutritivo, ao contrário do que é observado para o azevém. Esses resultados superam os valores encontrados em três anos de avaliação de aveia IAPAR 61 e azevém comum, que foram, respectivamente, $48,6 \%$ e $50,0 \%$ de NDT (RODRIGUES et al., 2002), indicando que as forrageiras avaliadas no presente trabalho apresentam alto valor nutritivo e são apropriadas para os climas temperados da região sul do país.

Para a variável teor de FDN (Tabela 3), observa-se um aumento no teor de FDN das forrageiras, à medida que são atrasadas as semeaduras, à exceção do trigo, que ocorreu o inverso. O teor de FDN é um dos importantes parâmetros de valor nutritivo da forragem e está inversamente proporcional à digestibilidade e ao consumo de matéria seca, por isso é de extrema importância descobrir qual a melhor combinação forrageira e época de semeadura. Comparando as espécies forrageiras, observou-se que, em média, o azevém comum apresentou maior teor de FDN, 4,7 pontos percentuais a mais que a aveia IAPAR 61, que apresentou o menor valor de FDN. GOMES \& REIS (1999), em três anos de experimento, constataram que a média dos teores de FDN para a aveia IAPAR 61 foi $48,6 \%$, na aveia UPF-

Tabela 2 - Teor médio de nutriente digestível de forrageiras anuais de inverno (NDT, \%) em diferentes épocas de semeadura. Dois Vizinhos - PR, 2008.

\begin{tabular}{|c|c|c|c|c|c|}
\hline \multirow{2}{*}{ Forrageira } & \multicolumn{5}{|c|}{-Época de semeadura--- } \\
\hline & 04 abril & 24 abril & 14 maio & 03 junho & Média \\
\hline Av. IPR 126 & $68,2 \mathrm{Aa}$ & $68,0 \mathrm{Aa}$ & $66,8 \mathrm{Ab}$ & $59,5 \mathrm{Bc}$ & 65,6 \\
\hline Av. IAPAR 61 & $70,1 \mathrm{Aa}$ & $68,2 \mathrm{Aa}$ & $65,7 \mathrm{Ab}$ & $62,4 \mathrm{Abc}$ & 66,6 \\
\hline Av. comum & $68,4 \mathrm{Aa}$ & $70,6 \mathrm{Aa}$ & $66,7 \mathrm{Ab}$ & $64,9 \mathrm{ABb}$ & 67,6 \\
\hline Az. Comum & $68,8 \mathrm{Aa}$ & $63,6 \mathrm{Ab}$ & $59,2 \mathrm{Bc}$ & $60,2 \mathrm{Bbc}$ & 62,9 \\
\hline Trigo Tarumã & $59,2 \mathrm{Bb}$ & $66,9 \mathrm{Aa}$ & $67,1 \mathrm{Aa}$ & $67,7 \mathrm{Aa}$ & 65,2 \\
\hline Média & 66,9 & 67,5 & 64,9 & 62,9 & \\
\hline
\end{tabular}

Valores seguidos de mesma letra maiúscula na coluna e minúscula na linha não diferem significativamente entre si pelo Teste de Duncan a $1 \%$. 
Tabela 3 - Teor médio de fibra em detergente neutro de forrageiras anuais de inverno (FDN, \%) em diferentes épocas de semeadura. Dois Vizinhos - PR, 2008.

\begin{tabular}{|c|c|c|c|c|c|}
\hline \multirow{2}{*}{ Forrageira } & \multicolumn{5}{|c|}{-Epoca de semeadura- } \\
\hline & 04 abril & 24 abril & 14 maio & 03 junho & Média \\
\hline Av. IPR 126 & $57,6 \mathrm{Bb}$ & $56,7 \mathrm{Ac}$ & $57,5 \mathrm{ABb}$ & $62,9 \mathrm{Aa}$ & 58,7 \\
\hline Av. IAPAR 61 & $55,4 \mathrm{Bb}$ & $55,4 \mathrm{Ab}$ & $56,1 \mathrm{Ba}$ & $56,8 \mathrm{ABa}$ & 55,9 \\
\hline Av. comum & $57,4 \mathrm{Bb}$ & $55,6 \mathrm{Ac}$ & $56,3 \mathrm{Bbc}$ & 59,9 Aa & 57,3 \\
\hline Az. Comum & $56,8 \mathrm{Bc}$ & $59,8 \mathrm{Ab}$ & $63,5 \mathrm{Aa}$ & $62,5 \mathrm{Aa}$ & 60,6 \\
\hline Trigo Tarumã & $67,0 \mathrm{Aa}$ & $58,6 \mathrm{Ab}$ & $57,5 \mathrm{ABb}$ & $54,8 \mathrm{Bc}$ & 59,5 \\
\hline Média & 58,8 & 57,2 & 58,2 & 59,4 & \\
\hline
\end{tabular}

Valores seguidos de mesma letra maiúscula na coluna e minúscula na linha não diferem significativamente entre si pelo Teste de Duncan a $1 \%$.

16, foi 49,6e, para o azevém comum, $53,0 \%$, com $140 \mathrm{~kg}$ de $\mathrm{N} \mathrm{ha}^{-1}$ em cortes intercalados de 28 dias, valores inferiores aos obtidos neste trabalho. Esta desigualdade possivelmente deve-se à metodologia de corte em datas pré-determinadas, manejo de adubação, localização geográfica de baixa altitude (13m), embora, em ambos os trabalhos, os teores de FDN são próprios de forrageiras de alto valor nutricional.

Comparando as forrageiras em cada época de semeadura, observou-se que, na primeira época, o maior teor de FDN foi obtido pelo trigo BRS Tarumã, e os menores pelas demais forrageiras que não diferiram entre si. Já na segunda época, não houve diferença significativa no teor de FDN entre as forrageiras, sendo que o teor médio de FDN foi de 57,2\%. MOREIRA et al. (2001), cultivando aveia-preta em 19 de abril, determinaram valores de FDN no primeiro e segundo cortes de 40,8 e 48,9\% em uma aplicação de $50 \mathrm{~kg}$ de nitrogênio, quando as plantas estavam com $10 \mathrm{~cm}$ de altura, deduzindo que, com o aumento das doses de nitrogênio, não há influência no teor de FDN, mas sim em relação ao envelhecimento das plantas que aumenta os elementos da parede celular. As aveias IAPAR 61 e aveia preta comum tiveram, respectivamente, 55,4 e $55,6 \%$ de FDN quando semeadas em 24 de abril, sugerindo que as plantas com altura de corte de $30 \mathrm{~cm}$ possuem teores maiores de FDN.

Na terceira época de semeadura, o azevém comum apresentou o maior percentual de FDN $(63,5 \%)$, seguido pela aveia IPR 126. ROCHA et al. (2007) semearam cultivares de aveia e azevém em meados de maio, adubando com nitrogênio 30 dias após a semeadura e, após cada corte, tiveram resultados médios de FDN para a aveia de $35,8 \%$ e para o azevém de $39,4 \%$. Os menores teores de FDN observados provavelmente estejam relacionados a germoplasmas mais apurados, no caso do azevém, métodos de uso de nitrogênio e forma de coletas, que aproveitaram os melhores estádios de desenvolvimento das forragens. Já para PRIMAVESI et al. (2001), em dois anos de pesquisa com a aveia IAPAR 61, obtiveram teores de 51,1 e 53,1\% de FDN, valores mais próximos aos obtidos neste ensaio. Averiguando a quarta época de semeadura, observa-se que a aveia IPR 126 e o azevém comum continuaram apresentando maior percentual que foi de 62,9 e $62,5 \%$, respectivamente, e o trigo BRS Tarumã teve o menor percentual, diferindo das outras forrageiras com 54,8\% de FDN. Novamente a dinâmica no valor nutritivo do trigo BRS Tarumã parece ser o causador da sempre significativa interação entre material forrageiro e data de semeadura para todas as variáveis de valor nutritivo. FEROLLA et al. (2008) determinaram teores de FDN de aveia preta no mês de abril de $64,28 \%$, em maio de $58,09 \%$ e em junho de $52,10 \%$, sendo que os valores superiores em abril foram atribuídos ao aumento do percentual de inflorescência e, dessa forma, dos constituintes da parede celular.

Diante do exposto, como foram realizados números de cortes diferentes entre os materiais, a possibilidade de se conseguir uma interessante dinâmica nutricional na estação de crescimento para os genótipos testados, deve ser considerada.

\section{CONCLUSÃO}

A época de semeadura interfere no valor nutritivo das plantas forrageiras, sendo que existe decréscimo neste quando as semeaduras são atrasadas a partir do início de abril. No entanto, o comportamento mais tardio do trigo BRS Tarumã resultou em um maior valor nutritivo, quando semeado em maio e junho, o que o torna interessante para compor misturas forrageiras que visem a estabilizar o valor nutritivo da pastagem ao longo do seu ciclo. 


\section{REFERÊNCIAS}

ALVES FILHO, D.C.A. et al. Características agronômicas produtivas, qualidade e custo de produção de forragem em pastagem de azevém (Lolium multiflorum Lam) fertilizada com dois tipos de adubo. Ciência Rural, Santa Maria, v.33 n.1, p.143-149, 2003. Disponível em: <http://www.scielo.br/pdf/ cr/v33n1/14157.pdf>. Acesso em: 23 jan. 2010. doi: 10.1590/ S0103-84782003000100023.

ALVIN, J.M.; CÓSER, M.J. Aveia e azevém anual: recursos forrageiros para a época da seca. In: CARVALHO, M.M.; ALVIM, M.J. (Eds.). Pastagens para gado de leite em regiões de influência da Mata Atlântica. Coronel Pacheco: EMBRAPA/CNPGL, 2000. p.83-107.

BHERING, S.B. et al. Mapa de Solos do Estado do Paraná: legenda atualizada. Rio de Janeiro: EMBRAPA/IAPAR, 2008. 74p.

BLASER, R.E. Pasture-animal management to evaluate plants and to develop forage systems. In: SIMPÓSIO SOBRE MANEJO DA PASTAGEM, 9., 1988, Piracicaba, SP. Anais... Piracicaba: FEALQ, 1988. p.1-39.

CECATO, U. et al. Avaliação de cultivares e linhagens de aveia (Avena spp.). Acta Scientiarum. Maringá, v.20, n.3, p.347354, 1998. Disponível em: <http://periodicos.uem.br/ojs/ index.php/ActaSciAnimSci/article/viewFile/4372/2998>. Acesso em: 26 maio, 2010.

COMISSÃO DE QUÍMICA E FERTILIDADE DO SOLO (CQFS RS/SC). Manual de adubação e calagem para os Estados do Rio Grande do Sul e Santa Catarina. 10.ed. Porto Alegre: Sociedade Brasileira de Ciência do Solo / Núcleo Regional Sul, 2004. 400p.

DEL DUCA, L. et al. Trigo BRS Tarumã para duplo propósito no Rio Grande do sul. In: REUNIÃO DA COMISSÃO SULBRASILEIRA DE PESQUISA DE TRIGO SEMINÁRIO TÉCNICO DO TRIGO, 36., 2004, Passo Fundo, RS. Atas e resumos... Passo Fundo: Embrapa Trigo, 2004. 152p.

FEROLLA, F.S. et al. Composição bromatológica e fracionamento de carboidratos e proteínas de aveia-preta e triticale sob corte e pastejo. Revista Brasileira de Zootecnia, Viçosa, v.37, n.2, p.197-204, 2008. Disponível em: <http:// www.scielo.br/pdf/rbz/v37n2/04.pdf>. Acesso em: 15 jun. 2010. doi: 10.1590/S1516-35982008000200004.

IAPAR (INTITUTO AGRONÔMICO DO PARANÁ). Disponível em: <http://www.iapar.br/arquivos/File/folhetos/ aveiapreta/aveiabrancapreta.html>. Acesso em: 25 nov. 2008.

GOMES, J.F.; REIS, J.C.L. Produção de forrageiras anuais de estação fria no litoral do Rio Grande do Sul. Revista brasileira de zootecnia, Viçosa, v.28, n.4, p.668-674, 1999. Disponível em: <http://www.revistasbz.org.br/scripts/revista/sbz1/Artigos/ 2310.PDF>. Acesso em: 23 maio, 2010.
MAACK, R. Geografia Física do Estado do Paraná. Curitiba: Universidade Federal do Paraná e Instituto de Biologia e Pesquisa Tecnológica, 1968. 350p.

MARTEN, G.C.et al. Near infrared reflectance spectroscopy (NIRS). Washington: USDA, 1985. 110p.

MOREIRA, F.B. et al. Avaliação de aveia preta cv 'Iapar 61' submetida a níveis crescentes de nitrogênio em área proveniente de cultura de soja. Acta Scientiarum, Maringá, v.23, n.4, p.815-821, 2001. Disponível em: <http://periodicos.uem.br/ ojs/index.php/ActaSciAnimSci/article/view/2608/2151>. Acesso em: 30 jun. 2010.

NEUMANN, M.; LUPATINI, G.C. Sistemas de forrageamento e alternativas para intensificação da produção de carne bovina integrada a lavoura. In: ENCONTRO DE INTEGRAÇÃO LAVOURAPECUÁRIA DO SUL DO BRASIL, 2002, Pato Branco, PR. Anais... Pato Branco, CEFET-PR, 2002. p.217-243.

PIAZETTA, R.G. Produção e comportamento animal em pastagem de aveia e azevém, submetida a diferentes alturas de manejo. 2007. 80f. Dissertação (Mestrado em Ciências Veterinárias) - Universidade Federal do Paraná, Curitiba, PR. Disponível em: <http://dspace.c3sl.ufpr.br/dspace/bitstream/handle/1884/10590/ Disserta\%20A7\%E3oricardo.pdf;jsessionid=06100BA0FE3ABD6BFB 967F2D256FB394?sequence=1>. Acesso em: 20 jan. 2009.

PITTA, C.S.R. Produção animal e vegetal em trigo duplo propósito com diferentes durações de pastejo. 2009. 82f. Dissertação (Mestrado em Agronomia-Produção Vegetal) Curso de Pós-graduação em Agronomia, Universidade Tecnológica Federal do Paraná, Pato Branco, PR.

PRIMAVESI, A.C. et al. Indicadores de determinação de cortes de cultivares de aveia forrageira. Scientia Agrícola, Piracicaba, v.58, p.79-89, 2001. Disponível em: <http://www.scielo.br/ pdf/sa/v58n1/a14v58n1.pdf $>$. Acesso em: 13 jan. 2011. doi: 10.1590/S0103-90162001000100014.

ROCHA da, M.G. et al. Produção e qualidade de forragem da mistura de aveia e azevém sob dois métodos de estabelecimento. Revista Brasileira de Zootecnia, Viçosa, v.36, n.1, p.7-15, 2007. Disponível em: <http://www.scielo.br/pdf/rbz/v36n1/ a02v36n1.pdf $>$. Acesso em: 12 dez. 2010.

RODRIGUES, R.C. et al. Rendimento de forragem e composição química de cinco gramíneas de estação fria. Pelotas: EMBRAPA, 2002. (Comunicado Técnico, 77). Disponível em: <http://www.cpact.embrapa.br/publicacoes/download/comunicados/ comunicado77.pdf $>$. Acesso em: 05 jan. 2009.

ZONTA, E.P.; MACHADO, A.D. SANEST - Sistema de analise estatístico para microcomputadores. Pelotas: UFPEL, 1984. 76p. 